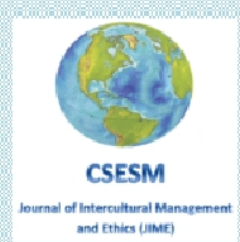

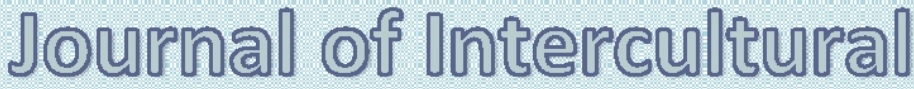

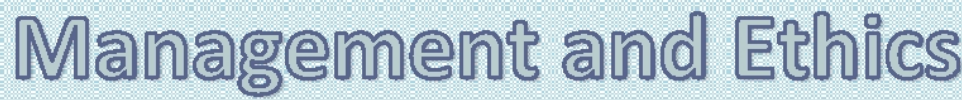

\author{
I0ME
}

ISSN 2601 - 5749, ISSN-L 2601 - 5749

Center for Socio-Economic Studies and Multiculturalism

lasi, Romania

WWW csesmioirg 


\section{TABLE OF CONTENT}

Editorial

Iulian Warter

Where Did Culture Come From? Evolutionary Foundations of Cultural Diversity

Paulo Finuras

Crash: Boeing and the Power of Culture

Thomas D. Zweifel, Vip Vyas

Political Culture, Social Polarization and Electoral Behavior. The Last Decade in Romanian

Political System

Silviu-Petru Grecu

The Principles of Transparency and Judging Others Favorably: The Talmudic View

Hershey H. Friedman, Robert B. Fireworker

Some Issues Regarding the Ethics of the Management at Romanian State-Owned

Companies .55

Baluta Aurelian Virgil, Rada Alexandru Cristian

How Does Logistics Command of the Military Navy Support Local Development and

Cultural Integration?

Rosa Caiazza

Illusion and Disillusion. Case Studies about the Constitution of a New Political Party in

Romania

Alexandru Muraru

How Could We Overcome the Feeling Of Insecurity? Explorations in the Spectrum of Polyscopic Consciousness

Anton Carpinschi

The Employees' Perceptions, Practices and Experiences Regarding the Strategic Process

Carried Out In the Public Hospitals

Ana Niculita 


\title{
HOW COULD WE OVERCOME THE FEELING OF INSECURITY? EXPLORATIONS IN THE SPECTRUM OF POLYSCOPIC CONSCIOUSNESS
}

\author{
Anton Carpinschi, $\mathrm{PhD}$ \\ Professor Emeritus \\ „Alexandru Ioan Cuza” University of Iaşi, Romania \\ E-mail: anton.carpinschi@gmail.com
}

\begin{abstract}
In search of a way to overcome the feeling of insecurity, this essay proposes a reflexive-therapeutic scenario inspired by the existence of subtle links between the knowledge of sensitive realities and the contemplation of intuitive transcendences. According to this scenario, the ordering Logos of the universe is configured in the horizon of human consciousness as personalized logicity multiplied in a series of hypostases. The idea of the hypostases of logicity configured in the horizon of the human consciousness led to the elaboration of the spectral model of the polyscopic consciousness. This mental tool helps us to understand how the hypostases of logicity foreshadow the experiential states of consciousness and also how the experiential states of consciousness assimilate the hypostases of logicity. Endowed with reflexive-therapeutic and educational valences, the polyscopic consciousness offers us, through the cooperation of its experiential states and the extension of the cultural horizon, the chance to overcome the fear and the complexes generated by the feeling of insecurity.
\end{abstract}

Keywords: polyscopic consciousness, hypostases of logicity, therapeutic self-reflexivity, dialogical-comprehensive thinking, dialogical-creative thinking, transdisciplinary model of thinking.

\section{Introduction}

"The puzzle of consciousness can be viewed in different ways, from those who consider consciousness a supernatural mystery that eludes natural explanations forever, to those who see in consciousness an extremely complicated natural phenomenon of which we know very little. And as time goes on, the blue line between the two modes becomes thinner and thinner. There are also those who express a skeptical attitude about the existence of consciousness as a real phenomenon or about the coherence of its conceptual foundation, as well as others with a much more positive conception who build their own considerations on consciousness to solve the puzzle" (Güzeldere, 1997, p.2). Starting from these preliminary observations on the nature of consciousness, I propose to sketch a conceptual-theoretical model with reflexive-therapeutic and educational valences that I call, the polyscopic consciousness and the spectrum of its experiential states.

\section{The spectrum of polyscopic consciousness. About the configuration of the hypostases of logicity on the horizon of the human consciousness}

But first, a clarification. Inspired by the structural ontology developed by Nicolai Hartmann through the reconstruction of the real world based on a general theory of categories (Hartmann, 1975), several years ago, I advanced a model of thought layers (Carpinschi, 1995, p.41). I was writing then that, from a temporal perspective, thinking in its process of emancipation and specialization is structured on the following layers: proto-logical, paralogical, logical, meta-logical. The model of thought layers has a double opening: towards the 
becoming of human thought in time and,simultaneously, towards the structuring of thought in its relations with the world. In this way, positioning the levels of thought, we tried a schematic configuration of the dynamics of the layers of human thought.

In the circumstances of configuring the spectrum of polyscopic consciousness, I think that the pattern of thought layers should be revised and supplemented. I am considering a change of perspective: from the analytical model of the layers of thought elaborated by an external observer, to the phenomenological model of the states of consciousness of the participating observer. When I refer to the states of consciousness of the participating observer I mean that, as an observer participating in the spectacle of the universe and the world, I can think and speak of the Logos as universal ordering spirituality because the Logos transpires in the horizon of my consciousness in the form of the hypostases of the logicity. Human logicity does not mean excessive rationalism, nor fixation on calculation and accounting, but the personalized perception of the Logos through the cognitive, affective, volitional assimilation of the hypostases of logicity. From what has been said so far we can deduce that, in order to assimilate the huge volume of information, knowledge, experiences contained in the hypostases of logicity, we need a certain type of consciousness ready to assimilate and cultivate them. I call this type of consciousness: polyscopic. Through its experiential states, the polyscopic consciousness assimilates, processes, capitalizes in cognitive, affective, volitional plan the hypostases of logicity, thus opening the way to understanding the world, assuming normality, explaining the abnormality, expanding the cultural horizon, the practice of reflexive therapy.

And now, the hypothesis of the experiential states of the polyscopic consciousness: the polyscopic consciousness assimilates, processes, capitalizes the hypostases of logicity in cognitive, affective, volitional plan through its experiential states: the common knowledge, scientific research, philosophical reflexivity, the spiritual-religious experience, artistic sensibility, ideological choice. The connections that are established between the experiential states of the polyscopic consciousness and the hypostases of logicity are explained by the fact that each experiential state of the polyscopic consciousness assimilates, processes, capitalizes a certain hypostasis of logicity and its connections with the other hypostases. Thus, common knowledge is the daily cognitive experience through which we process and capitalize on the protological hypostasis that underlies the implicit, spontaneous logicity, present in the forms and processes of natural thinking engaged in solving immediate problems. Supported trough the protological hypostasis, the common knowledge prepares the appearance of the other experiential states of the polyscopic consciousness as expressions of the hypostases of logicity. I have in my mind the scientific research logically grounded; philosophical reflexivity as a metalogical excursus; the spiritual-religious experience in the noological horizon; artistic sensibility with its perilogical emotions and vibrations; ideologically oriented political activity. Each experiential state of the polyscopic consciousness prepares from a cognitive, affective, volitional perspective the assimilation, processing, capitalization of a hypostasis of logicity, as well as its connections with the other hypostases. Thus, the spectrum of the experiential states of the polyscopic consciousness is outlined. After this first configuration, I feel the need to explain and legitimize from an ontological-epistemological point of view the conceptual-theoretical model of the polyscopic consciousness.

\section{The spectral model of polyscopic consciousness. A phenomenology of the hypostases of logicity and of the experiential states of the human consciousness}

A first question meant to contribute to make explicit the spectral model of the polyscopic consciousness could be formulated as follows: how is the presence of the previously identified experiential states in the spectrum of the polyscopic consciousness justified ? The experiential states identified in the spectrum of polyscopic consciousness 
respond to major needs and aspirations of the human being. Thus, common knowledge is the sum of cognitive experiences vital to solving current needs and understanding the problems of human coexistence. Accumulated in time with the help of immediate, empirical means, the common knowledge is the basis of our existence, inspiring, at the same time, the other experiential states of the polyscopic consciousness. Thus, by expanding systematized knowledge based on the use of standardized methods and techniques, scientific research appears that brings us closer to understanding the causes, laws, and trends that explain phenomena and processes in nature, society, thinking. But in search of ways to cultivate wisdom, philosophical reflexivity is the existential-reflexive experience which, by finding measure, the exercise of discernment, the practice of common sense reveals the natural limits of common knowledge, the errors of scientific research, the fragility and the pathologies of artistic sensitivity, the excesses of the religious fundamentalisms and the risks of ideological choices. At the heart of common knowledge are, in all their richness and diversity, the spiritual-religious experiences, major existential experiences in emotional-symbolic terms through which we entrust the anxieties and hopes of an all-powerful Entity above our powers. Also, in the core of common knowledge is born artistic sensibility, that experiential state through which we express our feelings in an artistic way and educate our good taste by contemplating creations in literature, dramatic art, music, choreography, visual arts, cinema. And, also in the core of the common knowledge are coagulated the ideological options through which we express our preference for a certain way of political organization and (re) allocation of positions, functions and resources in the society in which we live.

Another question meant to contribute to the explication of the spectral model of the polyscopic consciousness could be formulated as follows: why did the logicity and its hypostases appear in the spectral model of the polyscopic consciousness ? The polyscopic consciousness and its experiential states, as well as logicity and its hypostases, are not some words and phrases lined in a terminological dictionary to be then listed by a possible curious reader. As I announced at the beginning of this essay, I set out to develop a phenomenological model of the experiential states of polyscopic consciousness through awareness of the hypostases of logicity. As an observer participating in the spectacle of the universe and the world, I can think and talk about the ordering Logos of the universe and the world because the Logos transpires in the horizon of my consciousness in the multiplied form of the hypostases of my own logicity. As a personalized perception of the Logos, logicity through its hypostases foreshadows the experiential states of the polyscopic consciousness. The phenomenology of the hypostases of logicity thus confers epistemological legitimacy to the conceptual-theoretical model of the experiential states of the polyscopic consciousness.

But does the spectral model of polyscopic consciousness have any practical purpose ? Beyond the conceptual-theoretical finality, the spectral model of the polyscopic consciousness has a reflexive-therapeutic and educational finality that could be formulated as follows: overcoming the feeling of insecurity by enriching the states of polyscopic consciousness and thus finding the self beyond itself. With the help of the spectrum of its experiential states connected to the hypostases of logicity, the polyscopic consciousness opens numerous perspectives and possibilities for finding the self beyond the self. I mean a culturally enriched self, able to overcome its fears and complexes generated by the feeling of insecurity. At the same time, operationalized in the form of dimensions, indices and indicators specific to case studies and field research, the hypostases of logicity and experiential states of polyscopic consciousness could function as parameters for testing the level of logicity and expanding the cultural horizon of each of us. But, until the case studies and research reports, interdisciplinary teams, appropriate working tools tested on representative samples objectives that obviously go beyond the scope of this essay - I will present the hypostases of logicity through the filter of experiential states of polyscopic consciousness . 
The configuration of the hypostases of logicity transpires in the cooperation of the experiential states of the polyscopic consciousness since the prehistory of humanity. In the evolution of the human species, against the background of its bio-genetic evolution, in the period between 70,000 years ago and 30,000 years ago, a process of major importance took place: the cognitive revolution. According to paleoanthropological research, increasing the capacity to transmit information about the world around us, intertribal relationships, the imaginary universe of spirits and dreams led to spectacular results in increasing the capacity for innovation and planning, cooperation and execution of complex actions in relatively large groups (Harari, 2017, p.13-26). In this bio-socio-cognitive context, the hypostases of logicity began to foreshadow gradually in the horizon of Homo sapiens consciousness. Thus, the protological hypostasis outlined in the thinking of our distant ancestors became the basis of empirical knowledge, undifferentiated, unspecialized but extremely plastic and versatile through which the human species conquered the world. But the protological hypostasis is not only the oldest layer in the development of human thought. The protological hypostasis is found in all people of all times, functioning as the basic hypostasis of thought, the logical substrate of common knowledge. This deep-rooted bio-socio-cognitive context led me to use the composite term "proto-logical" with the meaning of knowledge at first sight, current knowledge, ante-theoretical knowledge. In this basic hypostasis of mental activity, the informational-operational mechanisms of primary information processing - sensations, perceptions, representations - are naturally intertwined with the mechanisms of secondary information processing: thinking, memory, imagination. It is thus constituted in the flow of the common language, the informal logical language, "an elementary and global logical system, which is able to ensure a certain level of logicity of current thinking" (Botezatu, 1983, p.165). The logic of current thinking gives us the rational tools by which we become capable of daily orientation in space and time, of reasonable choices and appropriate behaviors in the world. Against the background of the protological hypostasis, the germs of the other hypostases of human logic are born.

The improvement and specialization of thinking operations allowed the leap from protological to logical, from common knowledge to scientific research. Logical, as a hypostasis of logicity, is the object of logic as the science of forms, operations and laws of correct thinking. The history of logic - from the Aristotelian Organon of deductive logic and the Novum Baconian Organum of inductive logic to contemporary logical pluralism demonstrates the capacity of logic to open to reality, thematic multiplication and methodological generalization. This situation made logic present itself not only as a theory of thought and language, but also as a theory of action and reality. The current use of logic as a research tool of reality, nature, society, history, economics, politics, etc. contributed to the emergence and development of the research logic to which Karl R. Popper, for example, dedicated in the 30 s of the last century the famous treatise with the same name. At the same time, the progress of the formalization and operationalization of axiomatic systems, the multiplication of natural and formal languages, the proliferation of "non-classical" logics and the assault of logical pluralism led to the emergence of metalogic as a metatheoretical overspecialization of logic and a place of philosophical reflexivity.

The refinement of the reflexive capacity took place by configuring the metalogical hypostasis. The reflexive-comprehensive capacity of the metalogical hypostasis is explained by the fact that the metalogical is not just a logic of logic, a thinking-about-thinking. The metalogical hypostasis of logicity goes beyond the logical hypostasis because the metalogical hypostasis is the thinking-about-the-being-who-thinks. Referring to the thinking-about-thebeing-who-thinks, the metalological hypostasis offers to the logicity and, implicitly, to the philosophical reflexivity an opening with meaning, an opening towards the ontological. For example, Heidegger's ontology is "essential thinking about being" (Heidegger, 2003); 
Noician ontology is the essential thinking about "becoming of being." (Noica, 1998). But, the opening of the metalogical hypostasis acquires consistency and meaning when, simultaneously with the ontological opening, the asymptotic path of truth is opened. And the opening to the gradual and endless understanding of truths and infinite truth is the meaning of wisdom. These openings of the metalogical hypostasis make possible the meeting-in-wisdom of philosophical reflexivity with the paradoxes of life, challenges of science, expressions of art, the impulses of ideological options, but also with the spiritual-religious experiences.

From the perspective of the spectral model of the polyscopic consciousness, the spiritual-religious experience appears as, the experiential state that assimilates in cognitive, affective, volitional plan the noological hypostasis of logicity. I use the term "noological" because this term created by the French physicist André-Marie Ampère "to designate all the sciences that study the spirit, as opposed to the cosmological sciences" (Lalande, 1991, p.688) has the semantic power to concentrate the diversity of spiritual-religious experiences in the direction of the search of the Nous, the universal ordering spirituality. Returning to the universe of polyscopic consciousness, I think I can use the term "revelable" when I refer to the potential of noological experience to approach total knowledge in the hope of the salvation of the soul. Noological experience is revelable in the sense that it expresses the spiritual readiness of the polyscopic consciousness to receive the gift of divine revelation. Through the noological hypostasis of logicity we can listen to the voice of the Nous, the ordering principle of the cosmos (kósmos noetós), but also of our active intellect (nous poietikos). This uplifting work of the polyscopic consciousness is possible because the spiritual-religious experience assimilates the noological hypostasis of logicity through the penetrating power of cognition, the intensity of the affective experience, the sustained will of self-transcendence. Together, these faculties cultivate the spiritual readiness of the polyscopic consciousness to receive the gift of divine revelation. But, let us continue to explore the horizons of the polyscopic consciousness where the spiritual-religious experience meets the artistic sensibility.

As an experiential state of the polyscopic consciousness, artistic sensibility assimilates the perilogical hypostasis of the logicity. Remaining within the perimeter of logicity, artistic sensibility is expressed - lyrical, epic, dramaturgical, musical, visual-plastic, choreographic, cinematic - around logical truth with the help of the artistic means and the aesthetic truth. In other words, artistic sensibility expresses truth through the authenticity and depth of artistic experience. Artistic sensibility is, therefore, a specifically human experience in which logic is transfigured through the means of aesthetic creation and reception: metaphors, comparisons, allegories and other figures of speech; sound and color; melody and harmony; shapes and volumes; image and movement; rhythms and dance etc. The intrigue and the conflicts, the actions and the characters that cross the great literature, for example, are sometimes illogical and irrational, throwing us into an absurd world, but the whole composition in the writer's mind is a structural-perilogical artistic expression because it expresses in forms and artistic means the truth of human experience in all its complexity and paradoxes. And not infrequently, the complexity and paradoxes of human experience take the form of ideological choices and confrontations that accompany political disputes.

As an expression of the ideological hypostasis of human logicity, the ideological option is an ideatic-discursive arrangement with a political stake: supporting values and group interests in the (re)allocation of positions, functions and resources by controlling power relations. Both in the insufficiently elaborated form of the opinions and prejudices, and in the systematized form of programs and platforms developed by qualified people and specialized media tools, the ideological option motivates some interests and positions, tries to legitimize some social forces and actions and to destroy the positions and arguments of political opponents. Motivating the positions and interests of a social partiality, the ideological option 
is a politically involved thinking that projects a desirable over-reality for that social partiality. As an expression of multiple games of interest and power relations, the ideological option is an experiential state that combines the categories of subjectivity with those of the political instrumentalization of the subjectivity through ideologizing and propagandistic orchestration. In these circumstances, we witness or even participate in the penetration of the ideological hypostasis in the structures of society and in the states of the polyscopic consciousness where it exerts a strong impact.

Once here, some clarifications are required. First, when I refer to the richness and diversity of the experiential spectrum of polyscopic consciousness I do not mean the universal consciousness concentrated in an encyclopedic mind. I am referring only to the willingness of a person to find himself beyond himself by exploring the horizons of the polyscopic consciousness and experiencing his experiential states. Second, the experiential states that make up the spectrum of polyscopic consciousness are not in hierarchical relationships. Each of these existential experiences has its own specificity and its own purpose, contributing together to the configuration of the spectrum of the experiential states of the polyscopic consciousness. Third, through each experiential state of our own polyscopic consciousness we assume responsibilities because we initiate actions, mentally cause our own behavior, and trigger the reactions of others.

In conclusion, the cooperation of the experiential states of the polyscopic consciousness - from common knowledge, scientific research and philosophical reflexivity to spiritual-religious experience, artistic sensibility and ideological choice - highlights the plasticity of mental processes and the transdisciplinarity of thought operations. In these circumstances, I propose to follow more closely the mental processes behind the configuration of the spectrum of polyscopic consciousness as a personalized transdisciplinary model of thinking.

\section{Polyscopic consciousness or personalized transdisciplinary thinking. About therapeutic self-reflexivity}

The configuration of a personalized transdisciplinary model of thinking involves, in addition to operating the distinction between the referential plane and the self-referential plane, the introduction of a new important difference: multidisciplinarity and interdisciplinarity of the referential consciousness, on the one hand, transdisciplinarity of the self-referential consciousness, on the other. As it is known, the referential consciousness is configured multidisciplinary when, two or more disciplines research the same topic from the perspective of its own object, its own methodology and own finality. Thus, politics can be researched from the perspective of traditional academic disciplines: political science, sociology, psychology, constitutional law, history, human geography, geopolitics, political philosophy, etc. Multidisciplinary approaches do not exclude tensions between academic disciplines and researchers of these disciplines.

The referential consciousness is configured interdisciplinary when different disciplines collaborate, through a transfer of knowledges, concepts and methodologies, on the horizon of a common theme and/or cognitive strategy. For example, the design of an interdisciplinary psycho-sociological research on topics such as: electoral behavior, decisionmaking process, leader profile, etc. Or, the design of an interdisciplinary research that, engaging at the normative and reflexive levels, aims at exploring the origins of authority and legitimizing power, delegating and managing political power, researching the institutional mechanisms of politics and the rule of law, etc. Such interdisciplinary projects engage the philosophy of law, constitutional law, state theory, the science of organizations, etc. As with the multidisciplinary approaches, interdisciplinary tensions are not excluded. Despite the diversification of knowledge through multidisciplinary approaches, despite information- 
methodological transfers through interdisciplinary approaches, the purpose of such researches remains a referential one, more precisely, uni-referential, one related to a particular reference system according to the topic and strategy adopted. In the examples presented above, it is about multidisciplinary and interdisciplinary policy configuration. In these circumstances, what does the transdisciplinary vision bring new ?

The transdisciplinary vision differs in relation to multidisciplinary and interdisciplinary approaches from several points of view. I refer to the perspective, manner and finality of the transdisciplinary approach compared to multidisciplinary and interdisciplinary approaches. While the multidisciplinary and interdisciplinary perspectives are that of the external observer, the transdisciplinary perspective is that of the internal observer who monitors his own cognitive process. If the multidisciplinary and interdisciplinarity researches refer to the referential modalities of consciousness, modalities of the natural attitude based on external knowledge of objects by the knowing subject, transdisciplinarity refers to the self-referential capacity of polyscopic consciousness, the capacity of my consciousness to live and monitor various experiential states. Polyscopic consciousness becomes self-referential when it assumes its own experiential states through a transdisciplinary vision capable of capturing the dynamics, interferences and mutual transfers of suggestions and ideas between common knowledge, scientific research, philosophical reflexivity, spiritual-religious experience, artistic sensibility, ideological choice. These interferences and mutual transfers of suggestions and ideas create a transdisciplinary field of experiential states in the horizon of which the spectrum of poliscopal consciousness offers a comprehensive opening, from monitoring mental representations to the inner voice of morality and spiritual-religious experiences, from scientific research to reality artistic experience and the ideological justification of interest groups in the terrible confrontations of life. Regarding the finality, unlike the multidisciplinary research that remains, mainly, descriptive and analytical and unlike the interdisciplinary research that sometimes aims at practical-applied objectives, the transdisciplinary vision being self-referential and self-reflexive acquires therapeutic and educational valences.

The transdisciplinary exploration of the horizons of the polyscopic consciousness is favored, therefore, by the penetration of the therapeutic self-reflexivity in the experiential interiority of one's own mental activity. Unlike reflexivity, which is an impersonal discourse about self-thinking thinking with the help of concepts and conceptual structures, therapeutic self-reflexivity marks an important change of perspective: assuming therapeutic reflexivity in a personal name. Becoming a term of reference, the personal pronoun "I" imprints the mark of self-referentiality. Self-reflexivity is self-referential, expressing itself through its own conceptual-experiential structures in a first-person discourse. As a therapeutic reflexion, selfreflexivity participates in the exploration of self-awareness in different life situations, as well as in the examination of acts of thought and the cultivation of reflexive processes useful for their own therapeutic and educational strategies. Being a personalized reflexive-therapeutic process characterized by cognitive, emotional, volitional self-control, therapeutic selfreflexivity offers, by configuring the spectrum of polyscopic consciousness, the measure of its comprehensive capacity and the example of its moral responsibility.

In conclusion, the detailed research of the spectrum of polyscopic consciousness goes beyond the objective of this essay. The review of the experiential states of the polyscopic consciousness highlighted, however, the extent of its transdisciplinary area, as well as the value of the reflexive-therapeutic and educational potential. The spectrum of polyscopic consciousness thus emerged as a reflexive-therapeutic model of self-organization of its experiential states. In the increasingly confusing and insecure world in which we live, the 
reflexive-therapeutic finality of the polyscopic consciousness appears, therefore, as a possible remedy.

\section{Polyscopic consciousness and overcoming the feeling of insecurity}

Diffuse and persistent, the feeling of insecurity felt by the man of late modernity is generated by numerous global processes with personal reverberations. Human civilization appears today in the form of a fragile competitive coexistence tense by the uncontrollable relations with the natural environment, demographic and gender imbalances, fierce competition for resources, financial-banking dysfunctions, economic and social disparities, geostrategic confrontation of superpowers against the background of the ideological-political disputes and the confessional-religious conflicts. Sharpened by the world financial engineering, stock markets speculation, ethno-nationalist impulses, politico-military conflicts, these structural tensions are increasingly turning into global and/or regional crises that generate a sense of diffuse insecurity on the background of which overlap our own identity narratives often laden with personal dramas and failures.

In these circumstances, a hypothetical-theoretical construct called the polyscopic consciousness tries to prove its opportunity for those looking for existential and action landmarks. Comprehensive and creative, the polyscopic consciousness opens through its experiential states a diversity of perspectives and connections that contribute to the mental reconstruction of the world and the self. The spectrum of experiential states of polyscopic consciousness thus reveals its reflexive-therapeutic and educational valences suggesting the idea that man, faillible by his nature, could overcome the feeling of insecurity by exploring the horizons of polyscopic consciousness and finding the self beyond self. Revealing the diversity of experiential states of consciousness, the spectrum of polyscopic consciousness offers the self the chance to find itself in a "new self" by living varied and enriching existential experiences that make it possible to overcome the feeling of insecurity.

But, how could one explain the capacity of the polyscopic consciousness to reveal the diversity of its experiential states and to open thus the horizons to varied and enriching existential experiences? What are the mechanisms of polyscopic thinking through which our deep self could overcome the feeling of insecurity? How does the spectrum of polyscopic consciousness help us to find the self beyond the self ? Living cognitive, affective, volitional experiences in different life contexts, evaluating situations and finding solutions through the practice of inner dialogue and interpersonal dialogue emancipate the self-awareness and encourage it to use the dialogical-comprehensive thinking and dialogical-creative thinking. In other words, the ideational process supported by the questions and answers generated by the inner dialogue of self-awareness, on the one hand, and interpersonal dialogue, on the other hand, shapes both the comprehensive thinking - thinking capable of deep understanding a situation by transposing us into that situation - as well as the creative thinking capable of innovative solutions. In order to name the self capable of generating and maintaining such a dialogue, I used the term "dialogical self" launched by Hubert Hermans and collaborators (Hermans et al., 1992, p.23-33). Thus, a conceptual apparatus was outlined - the dialogical self, dialogical-comprehensive thinking, dialogical-creative thinking - with the help of which I will try to decipher the mechanisms of polyscopic thinking and the chances of finding the self beyond the self.

In this order of ideas, I start from the following hypothesis: the dialogical self, as an ideational and operational center of the polyscopic consciousness, mediates with the help of dialogical-comprehensive thinking and dialogical-creative thinking the cooperation of the experiential states of the polyscopic consciousness. The experience of the states of the polyscopic consciousness opens to the dialogical self the way of finding itself beyond itself, thus offering it the chance to overcome the feeling of insecurity. The exploration of the 
experiential states of the polyscopic consciousness - from common knowledge, scientific research and philosophical reflexivity to spiritual-religious experience, artistic sensibility and ideological choice - offers to dialogical self the possibility of deepening self-knowledge and, thus, the chance to find a self more cultivated, more fulfilled. But, the rediscovery of the fulfilled self in cognitive, scientific, philosophical, spiritual-religious, artistic, ideological plan means the rediscovery of the dialogical self beyond the self, therefore, the rediscovery of a securized dialogical self. Awareness of the hypostases of logicity through the cooperation of experiential states specific to common knowledge, scientific research, philosophical reflexivity, spirit-religious experiences, artistic sensibility, ideological choice contributes, at the same time, to increase the comprehensive and creative capacity of the consciousness of self in its polyscopic horizon. Through the polyscopic consciousness and its experiential states, the dialogical self coagulates a self-referential system of understanding man's relations with the world, the universe, the divinity. Therefore, as vectors of mental causality, the dialogical self, the dialogical-comprehensive thinking and the dialogical-creative thinking generate a true modus operandi for finding the self beyond the self and thus overcoming the feeling of insecurity.

\section{Conclusions}

The spectral model of polyscopic consciousness is the result of an older intuition. The thinning of the demarcation line between the consciousness perceived as a natural phenomenon and the consciousness experienced as a supernatural mystery allowed, in the synthetic and practical spirit of therapeutic self-reflexivity, the transformation of the demarcation line into a bridge of encounter, a sign of dialogue and complementarity. The dialogue between the consciousness perceived as a natural phenomenon and the consciousness lived as a supernatural mystery became possible by configuring the hypostases of logicity in the horizon of the experiential states of the polyscopic consciousness. By exploring the horizons of the polyscopic consciousness, the polyscopic vocation of consciousness given to us by the Supreme Donor through the hypostases of logicity transpires.

\section{References}

Botezatu, P. (1983). Constituirea logicităţii. (The Constitution of Logicity). Bucharest: Scientific and Encyclopedic Publishing House.

Carpinschi, A. (1995). Deschidere și sens în gândirea politică. (Openness and meaning in political thinking), Iași: European Institute Publishing House.

Güzeldere, G. (1997). Introduction. The Many Faces of Consciousness: A Field Guide.In N. Block, O. J. Flanagan, \& G. Güzeldere (Eds.), The Nature of Consciousness: Philosophical Debates. Cambridge, Massachusetts: The MIT Press.

Harari, Y. N. (2017). Sapiens. Scurtă istorie a omenirii. (Sapiens. Short history of mankind). Iași: Polirom.

Hartmann, N. (1975). New Ways of Ontology. Westport, Connecticut: Greenwood Press.

Heidegger, M. (2003). Ființă și Timp. (Being and Time). București: Humanitas.

Hermans, H. J., Kempen, H. J., \& Van Loon, R. J. (1992). The Dialogical Self: Beyond Individualism and Rationalism. American Psychologist, 47 (1), 23-33.

Lalande, A. (1991). Vocabulaire technique et critique de la philosophie, Paris: Presses Universitaires de France.

Noica, C. (1998). Devenirea între ființă. Incercare asupra filozofiei tradiționale. Tratat de ontologie. (Becoming in Being. Test on Traditional Philosophy. Treatise on Ontology). București: Humanitas 